\title{
DEVELOPMENT AND VALIDATION OF NOVEL RP-HPLC METHOD FOR THE SIMULTANEOUS ESTIMATION OF ELLAGIC ACID AND QUERCETIN IN AN AYURVEDIC FORMULATION
}

\author{
SULTANA SHAIKH, VANDANA JAIN*
}

Department of Quality Assurance, Oriental College of Pharmacy, Sanpada-Navi Mumbai, Maharashtra 400705

Email: vandana.jain@ocp.edu.in

Received: 29 Apr 2018, Revised and Accepted: 24 May 2018

\begin{abstract}
Objective: To develop a novel, accurate, precise and linear reverse phase high performance liquid chromatographic (RP-HPLC) method for simultaneous qualitative and quantitative estimation of ellagic acid and quercetin in an ayurvedic formulation and validate as per international conference on harmonization (ICH) guidelines.
\end{abstract}

Methods: In the present work, good chromatographic separation was achieved isocratically using a shim-pack HPLC C18 column (4.6 x 250 mm, $5 \mu \mathrm{m}$ ) and a mobile phase consisting of $0.02 \mathrm{M}$ potassium dihydrogen orthophosphate buffer (pH adjusted to 3.5 with orthophosphoric acid) and acetonitrile in the ratio $60: 40$, at flow rate of $1.2 \mathrm{ml} / \mathrm{min}$ and column temperature maintained at $35{ }^{\circ} \mathrm{C}$. The effluents obtained were monitored at $255 \mathrm{~nm}$ with UV-visible detector.

Results: The retention time of ellagic acid and quercetin were found to be $1.65 \mathrm{~min}$ and 2.94 min respectively. Linearity of ellagic acid and quercetin were tested in the range of 6-14 ppm and 3-11 ppm respectively. The correlation coefficient for ellagic acid and quercetin were 0.997 and 0.993 respectively. The high recovery values (98 \%-102\%) indicate a satisfactory accuracy. The low percent relative standard deviation (\% RSD) values in the precision study reveals that the method is precise.

Conclusion: The developed method is novel, simple, precise, rapid, accurate and reproducible for simultaneous quantitative estimation of ellagic acid and quercetin in an ayurvedic formulation. Hence the developed method can be used for quantitative analysis and quality control of extracts and commercial samples of other plant species and formulation containing these two markers.

Keywords: Ellagic acid, Quercetin, Ayurvedic formulation, RP-HPLC, Validation, ICH

(C) 2018 The Authors. Published by Innovare Academic Sciences Pvt Ltd. This is an open access article under the CC BY license (http://creativecommons.org/licenses/by/4.0/) DOI: http://dx.doi.org/10.22159/ijap.2018v10i4.27011

\section{INTRODUCTION}

Ayurvedic medicines are polyherbal formulations and every herb consists of array of chemical constituents. Hence, each ayurvedic formulation is a source of many different phytochemicals, which individually may have different medicinal properties. The standardization parameters set for such polyherbal formulations are inadequate and therefore quality specifications are not stringent. Standardization is an important parameter for maintaining and accessing the safety and quality of herbal medicines as they are comprised of many chemical constituents and are capable of variation [1] therefore, the development of various novel analytical techniques for the analysis of medicinally active phytoconstituents has become an important step of standardization. The information generated from high performance thin layer chromatography (HPTLC) and high-performance liquid chromatography (HPLC) fingerprint profiles have a potential application in deciding the identity, purity, and strength of herbal medicines and also for fixing standards for herbal formulations [2].

In the present study we have selected an ayurvedic dental powder, which is used to maintain oral hygiene. It is indicated for various dental problems and makes teeth and gums stronger. The selected ayurvedic formulation contains Embelica officinalis (Phyllanthaceae), Terminalia chebula (Combretaceae), Terminalia belerica (Combretaceae) and other crude drugs. Two chemical markers were selected for quantification namely ellagic acid and quercetin.

The literature survey reveals that various analytical methods for estimation of ellagic acid and quercetin were reported alone and in combination with other drugs [3-8] also the simultaneous estimation of ellagic acid and quercetin along with other flavonoids by HPLC-DAD reported [9] but to the best of our knowledge there is no such reported HPLC-UV analysis method for simultaneous estimation of ellagic acid and quercetin in an ayurvedic dental formulation.

In the present investigation, we have developed a simple, optimized and validated HPLC method for the standardization of an ayurvedic formulation using two chemical markers namely ellagic acid and quercetin. The method was validated as per the international conference on harmonization (ICH) guidelines. This novel validated method has applicability in industry as well as in academia.

\section{MATERIALS AND METHODS}

HPLC grade ellagic acid and quercetin (purity 99\%) were procured as gift sample from Yucca Enterprises, Mumbai, India. An ayurvedic preparation Vicco vajradanti dental powder used for analysis was procured from local market. HPLC grade solvents were purchased from Thomas Baker. RP-HPLC shimadzu (LC 2030) model with "Lab Solution" software was employed in this method. Analytical column used for the separation of analytes was shim-pack HPLC C18 (250 X $4.6 \mathrm{~mm}, 5 \mu \mathrm{m})$.

\section{Methods}

\section{Selection of wavelength}

Suitable wavelength for the HPLC analysis was determined by recording UV spectrums in the range of 200-400 $\mathrm{nm}$ for individual drug solutions of ellagic acid and quercetin then overlapped. UV overlain spectra of these two markers showed that the drugs absorb appreciably at $255 \mathrm{~nm}$ and hence $255 \mathrm{~nm}$ was taken as a detection wavelength for HPLC analysis (fig. 1).

\section{Chromatographic conditions}

The method was developed using reverse phase, shim-pack HPLC C18 column ( $250 \times 4.6 \mathrm{~mm}, 5 \mu \mathrm{m})$. The run time was of $10 \mathrm{~min}$. The mobile phase used was $0.02 \mathrm{M}$ potassium dihydrogen orthophosphate buffer ( $\mathrm{pH}$ adjusted to 3.5 with orthophosphoric acid) and acetonitrile in the ratio $60: 40$ at a flow rate of $1.2 \mathrm{ml} / \mathrm{min}$, column temperature maintained at $35^{\circ} \mathrm{C}$ and a detection wavelength of $255 \mathrm{~nm}$ using a UV-visible detector.

\section{Preparation of $0.02 \mathrm{M}$ phosphate buffer ( $\mathrm{pH} 3.5$ )}

About $2.72 \mathrm{~g}$ of potassium dihydrogen orthophosphate was accurately weighed and dissolved in $950 \mathrm{ml}$ of water. The $\mathrm{pH}$ was 
adjusted to 3.5 with orthophosphoric acid and the volume was made up to $1000 \mathrm{ml}$ in volumetric flask. The solution was then filtered using $0.45 \mu$ membrane filter.

\section{Preparation of standard solution}

$100 \mathrm{mg}$ of ellagic acid and quercetin standard were accurately weighed and transferred into $100 \mathrm{ml}$ volumetric flask respectively. About $70 \mathrm{ml}$ solvent was added, sonicated to dissolve and diluted up to the mark using solvent (1000 ppm). Final concentration of ellagic acid and quercetin were made to $10 \mathrm{ppm}$ and $7 \mathrm{ppm}$ respectively by suitable dilutions.

\section{Sample preparation}

Accurately about $500 \mathrm{mg}$ of dental powder was extracted with $100 \mathrm{ml}$ methanol. The sample solution was filtered to obtain a clear solution. The stock solution after suitable dilutions was used for further analysis.

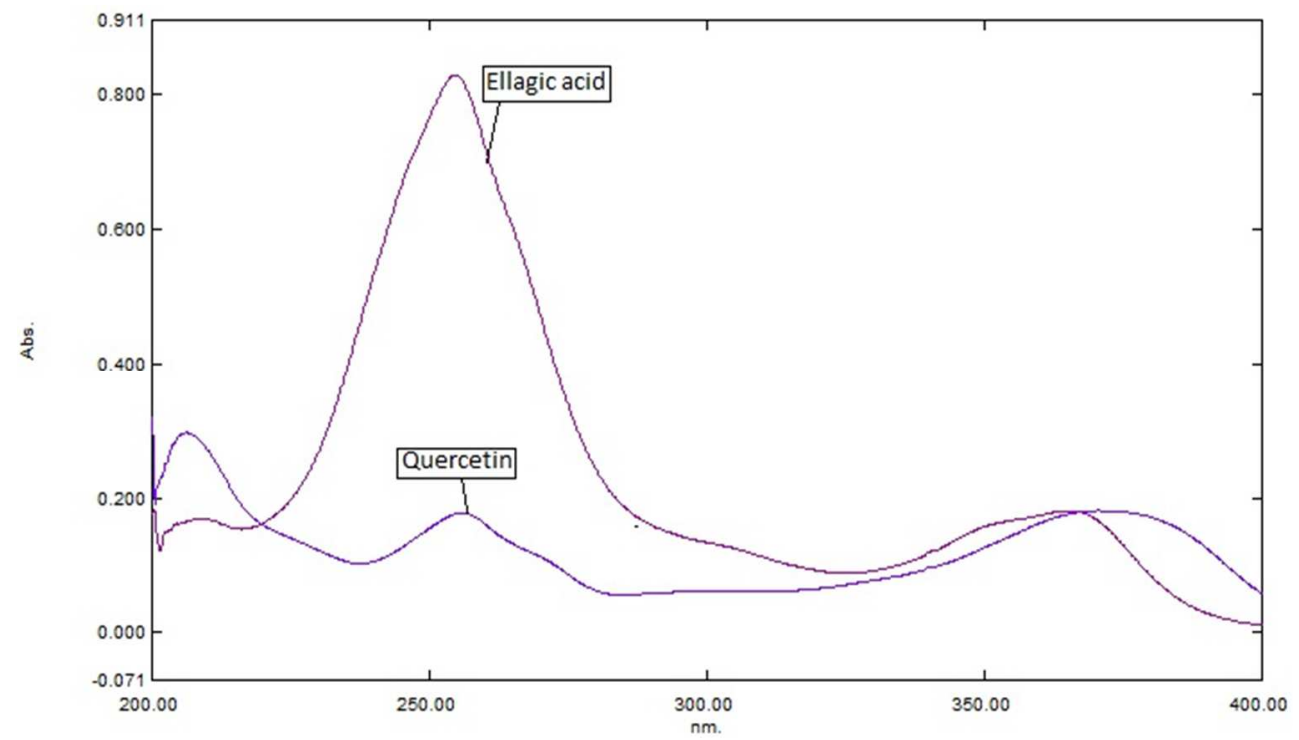

Fig. 1: UV overlap spectrum of ellagic acid and quercetin

\section{RESULTS AND DISCUSSION}

\section{Method development}

A reverse phase HPLC method was developed keeping in mind the system suitability parameters i.e. resolution factor between peaks, tailing factor, number of theoretical plates, runtime and the cost effectiveness. The developed optimized method resulted in the elution of ellagic acid at $1.65 \mathrm{~min}$ and quercetin at $2.94 \mathrm{~min}$. Fig. 2 and 3 represent chromatograms of ellagic acid and quercetin standard solution respectively. The total run time was $10 \mathrm{~min}$ System suitability tests are an integral part of method development and are used to ensure adequate performance of the chromatographic system. Retention time, number of theoretical plates, peak resolution and peak tailing factor were evaluated for six replicate injections of the standard working concentration.

The results given in table 1 were within the acceptable limits [10].

$\mathrm{mV}$

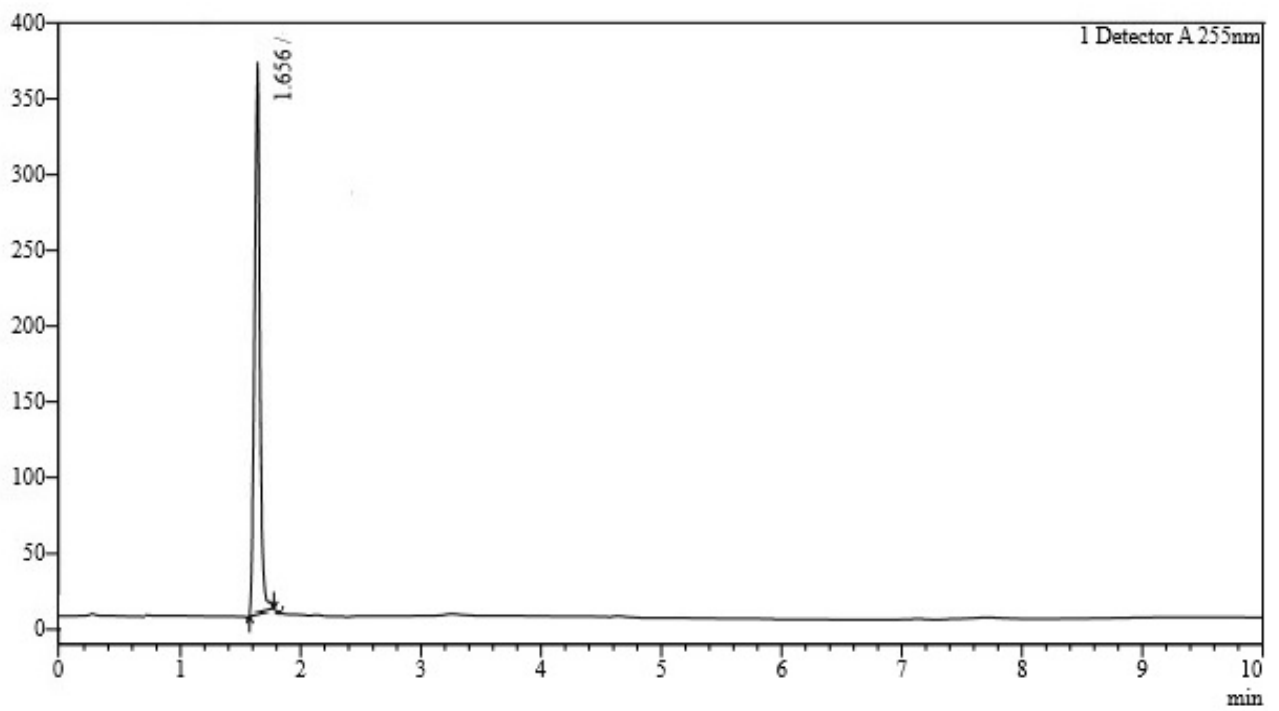

Fig. 2: Typical chromatogram of ellagic acid standard solution 
$\mathrm{mV}$

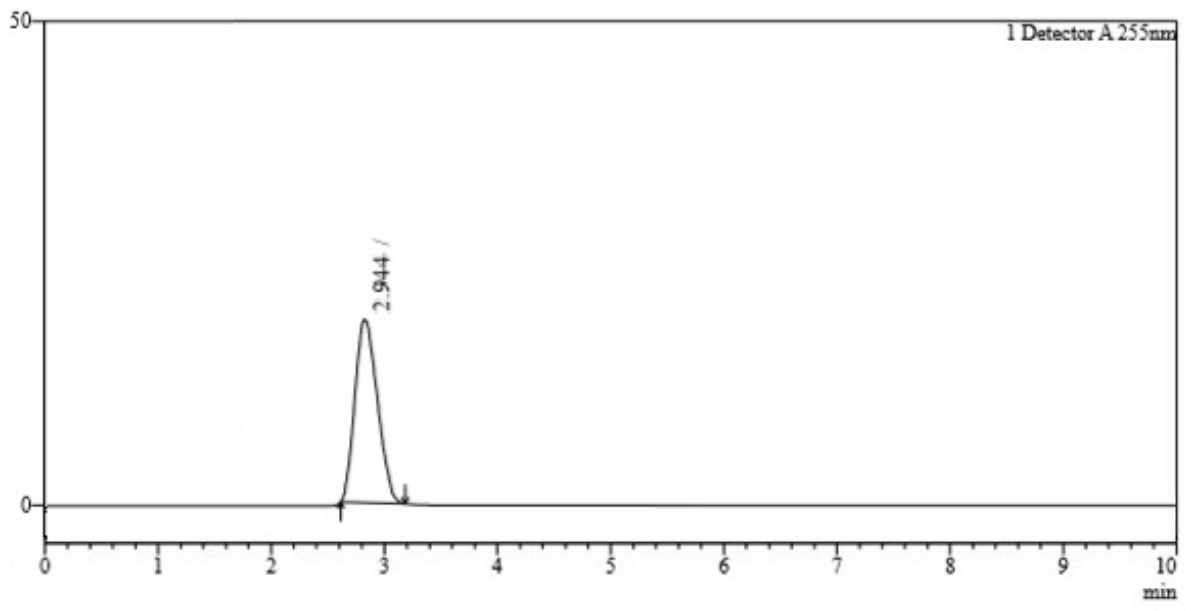

Fig. 3: Typical chromatogram of quercetin standard solution

Table 1: Result of system suitability studies

\begin{tabular}{|c|c|c|c|}
\hline Parameters & Acceptance limit & Ellagic acid & Quercetin \\
\hline Retention time (min) & - & 1.65 & 2.94 \\
\hline Resolution factor & Not less than 2 & - & 8.04 \\
\hline Number of theoretical plate & Not less than 2000 & 3608 & 3786 \\
\hline Tailing factor & Not more than 2 & 1.02 & 1.21 \\
\hline
\end{tabular}

In order to test the applicability of the developed method to an ayurvedic formulation, dental powder extracts were chromatographed and it is shown in fig. 4 . The sample peaks were identified by comparing the relative retention times with standard markers (fig. 2,3). System suitability parameters were within the acceptance limits, ideal for the chromatographed sample. Integration of separated peak area was done and each marker concentration was determined by using the peak area concentration relationship obtained in the standardization step. For the analysis of sample, extract of $500 \mathrm{ppm}$ of dental powder was injected in triplicate and quantified for two active markers using linear regression equation. The results of dental powder extract analysis are reported in table 2 .

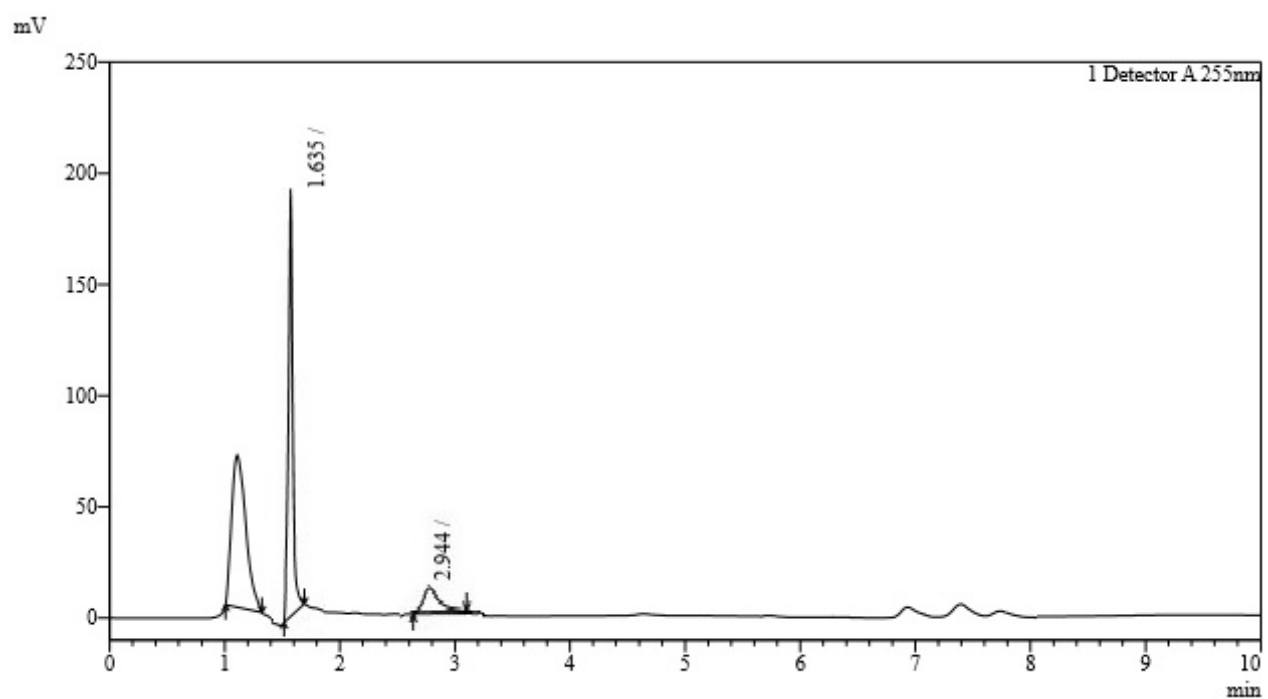

Fig. 4: Typical chromatogram of ayurvedic formulation

Table 2: Analysis of dental powder extract

\begin{tabular}{llll}
\hline Formulation & Marker & Amount found (ppm) $\mathbf{n = 3}$ & Content (\%) \\
\hline Dental powder extract & Ellagic acid & 3.86 & 0.77 \\
$(500 \mathrm{ppm})$ & Quercetin & 2.85 & 0.57 \\
\hline
\end{tabular}

\# n: number of injections $(n=3)$ 


\section{Method validation}

Validation of the analytical method is the process that establishes by laboratory studies in which the performance characteristics of the method meet the requirements for the intended analytical application. The developed HPLC method was validated according to ICH guidelines [11] for validation of analytical procedures. The method was validated for the parameters like linearity, accuracy, system precision, method precision, robustness, limit of detection and limit of quantitation.

\section{Specificity}

Fig. 2-4 for standard drug solutions and sample chromatograms reveals that the peaks obtained in the standard solutions and sample solution at working concentrations are only because of the drugs as blank has no peak at the retention time of ellagic acid and quercetin. Accordingly, it can be concluded that the method developed is said to be specific [12].

\section{Precision}

\section{System precision}

Six replicate injections of the standard solutions at working concentration showed percent relative standard deviation (\% RSD) less than 2 concerning peak area for each marker, which indicates the acceptable reproducibility and thereby the precision of the system $[13,14]$. System precision results are tabulated in table 3.

\section{Method precision}

Method precision was determined by performing the analysis of the sample under the test of repeatability at working concentration. Three injections of the sample from the same homogeneous mixture at working concentration showed \% RSD less than 2 concerning content of two markers indicate that the method developed is precise by the test of repeatability $[13,14]$ and hence can be understood that the method gives consistently reproducible results (table 4).

Table 3: System precision results

\begin{tabular}{lll}
\hline S. No. & Peak area of ellagic acid (10 ppm) & Peak area of quercetin (7 ppm) \\
\hline 1 & 1356692 & 405178 \\
2 & 1397586 & 409767 \\
3 & 1386532 & 402459 \\
4 & 1386582 & 409876 \\
5 & 1386239 & 403625 \\
6 & 1397528 & 402562 \\
mean \pm SD & $1385193 \pm 14986$ & $405578 \pm 3430$ \\
$\%$ RSD & 1.08 & 0.85 \\
\hline
\end{tabular}

\# SD: Standard deviation, \# \%RSD: Percent relative standard deviation, \# Result expressed in mean \pm SD and $n=6$

Table 4: Method precision results

\begin{tabular}{llll}
\hline \multirow{2}{*}{ Marker } & Intra-day & Inter-day \\
\cline { 2 - 4 } & Content $(\mathbf{p p m}) \mathbf{n = 3}$ & \% RSD & Content (ppm) n=3 \\
\hline Ellagic acid & 3.83 & 0.78 & 3.85 \\
Quercetin & 2.84 & 0.35 & 2.83 \\
\hline
\end{tabular}

\# n: number of injections (n=3), \# \%RSD: Percent relative standard deviation

\section{Linearity}

Standard solutions of ellagic acid and quercetin at different concentrations level were prepared in triplicates. Calibration curves were constructed by plotting the concentration level versus corresponding peak areas for each marker. The results show an excellent correlation between peak areas and concentrations level within the tested concentration range of 6-14 ppm for ellagic acid and as that of 3-11 ppm for quercetin (table 5). The correlation coefficients were greater than 0.99 for each marker, which meet the method validation acceptance criteria $[13,14]$ and hence the method is said to be linear (fig. 5, 6).

Table 5: Data from linearity studies

\begin{tabular}{lll}
\hline Marker & Concentration range (ppm) & $\mathbf{R}^{\mathbf{2}}$ \\
\hline Ellagic acid & $6-14$ & 0.997 \\
Quercetin & $3-11$ & 0.993 \\
\hline
\end{tabular}

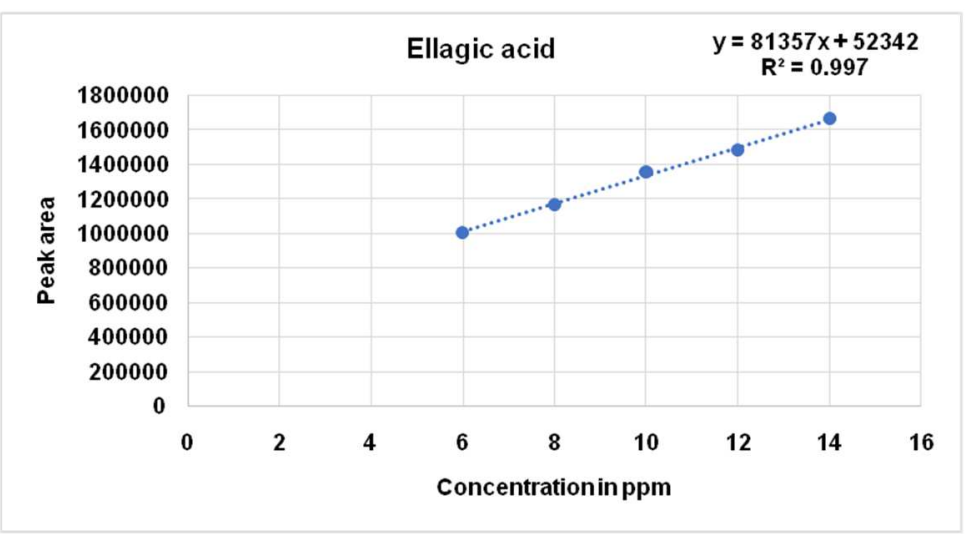

Fig. 5: Calibration curve of ellagic acid 


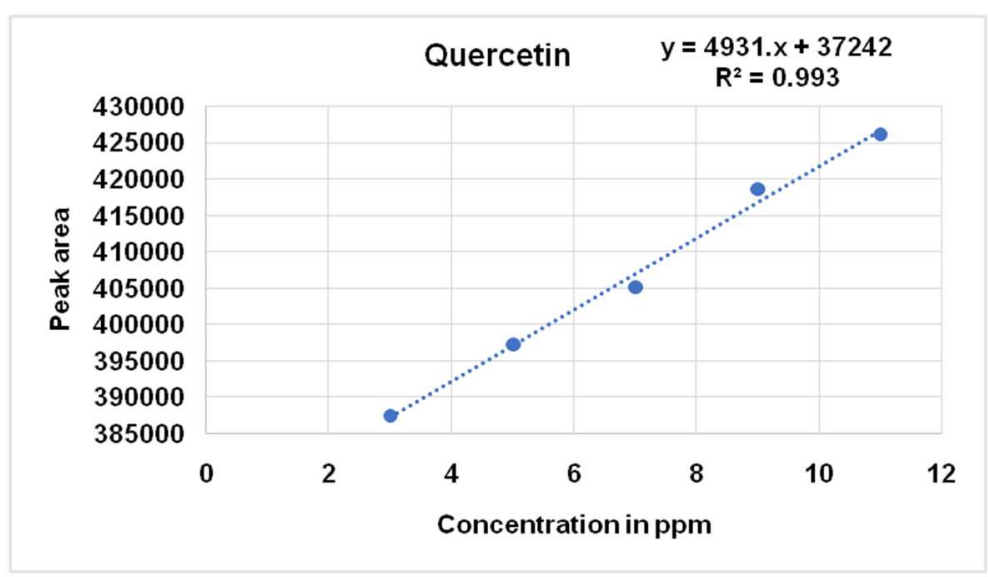

Fig. 6: Calibration curve of quercetin

\section{Accuracy}

Accuracy was determined by means of recovery experiments, by the determination of $\%$ mean recovery of each compounds in the formulation at three different levels (80\%, 100\% and120\%). At each level, three determinations were performed. Percent mean recovery was calculated as shown in table 6 . The accepted limits of mean recovery are $98 \%-102 \%$ and all observed data were within the required range, which indicates good recovery values, affirming the accuracy of the method developed $[13,14]$.

Table 6: Recovery study for two markers in dental powder

\begin{tabular}{|c|c|c|c|c|c|c|}
\hline Compounds & $\begin{array}{l}\text { Sample content } \\
\text { [ppm] }\end{array}$ & $\begin{array}{l}\text { Standard added } \\
\text { [ppm] }\end{array}$ & $\begin{array}{l}\text { Actual amount } \\
\text { [ppm] }\end{array}$ & $\begin{array}{l}\text { Total area found } \\
{[n=3]}\end{array}$ & $\begin{array}{l}\text { Amount recovered } \\
\text { [ppm] }\end{array}$ & $\begin{array}{l}\% \\
\text { Recovery }\end{array}$ \\
\hline \multirow[t]{3}{*}{ Ellagic acid } & 1.93 & 1.54 & 3.47 & 801379 & 3.41 & 98.45 \\
\hline & & 1.93 & 3.86 & 836549 & 3.84 & 99.70 \\
\hline & & 2.31 & 4.24 & 865239 & 4.20 & 99.09 \\
\hline \multirow[t]{3}{*}{ Quercetin } & 1.42 & 1.14 & 2.56 & 384998 & 2.54 & 99.57 \\
\hline & & 1.42 & 2.84 & 386510 & 2.85 & 100.55 \\
\hline & & 1.70 & 3.12 & 387645 & 3.08 & 98.90 \\
\hline
\end{tabular}

\# n: Number of injections $(n=3)$

\section{Robustness}

To determine the robustness of the developed method, experimental conditions were deliberately altered, and the system suitability parameter tailing factor and peak area were evaluated. The solution was prepared as per the test method described earlier and injected at different variable conditions like column temperature $\left(33^{\circ} \mathrm{C}\right.$ and $\left.37{ }^{\circ} \mathrm{C}\right)$, flow rate $(1.1 \mathrm{ml} / \mathrm{min}$ and $1.3 \mathrm{ml} / \mathrm{min})$ and detection wavelength (254 $\mathrm{nm}$ and $256 \mathrm{~nm}$ ). Robustness data clearly shows that the proposed method is robust at small but deliberate change $[13,14]$. Robustness data are given in table 7 .

Table 7: Robustness data for ellagic acid and quercetin

\begin{tabular}{llcc}
\hline Parameters & \multicolumn{2}{l}{ Ellagic acid (10 ppm) } & \multicolumn{2}{l}{ Quercetin (7 ppm) } & Peak area & Tailing factor & 0.98 \\
\cline { 2 - 4 } & Peak area & Tailing factor & 405178 \\
\hline Minus temp $\left(33^{\circ} \mathrm{C}\right)$ & 1356692 & 1.02 & 408768 \\
Plus temp $\left(37^{\circ} \mathrm{C}\right)$ & 1356786 & 1.00 & 0.97 \\
Minus flow rate $(1.1 \mathrm{ml} / \mathrm{min})$ & 1356825 & 1.08 & 404863 \\
Plus flow rate $(1.3 \mathrm{ml} / \mathrm{min})$ & 1357687 & 1.09 & 405283 \\
Minus wavelength $[254 \mathrm{~nm}]$ & 1357358 & 0.99 & 405834 \\
Plus wavelength $[256 \mathrm{~nm}]$ & 1367846 & 1.37 & 406834 \\
\hline
\end{tabular}

\section{Sensitivity}

The sensitivity of measurement of ellagic acid and quercetin by use of the proposed method were estimated in terms of the limit of quantitation (LOQ) and limit of detection (LOD).
LOQ and LOD were calculated by the use of the equations LOD = $3.3 \sigma / \mathrm{S}$ and $\mathrm{LOQ}=10 \sigma / \mathrm{S}$ where $\sigma$ is the standard deviation of intercepts of calibration plots and $S$ is the average of the slopes of the corresponding calibration plot (table 8).

Table 8: LOD and LOQ for ellagic acid and quercetin

\begin{tabular}{lcl}
\hline Marker & LOD (ppm) & LOQ (ppm) \\
\hline Ellagic acid & 0.60 & 1.84 \\
Quercetin & 0.45 & 1.60 \\
\hline
\end{tabular}

\# LOD: limit of detection, \# LOQ: limit of quantitation 
The results obtained from above set of observations prove that the method is useful in qualitative and quantitative analysis of the two markers from the complex herbal mixture formulation. Moreover, various analytical methods for estimation of ellagic acid and quercetin were reported alone and in combination with other drugs [3-8] also simultaneous estimation of ellagic acid and quercetin along with other flavonoids by HPLC-DAD reported [9] but as yet there is no reported HPLC-UV analysis method for simultaneous estimation of ellagic acid and quercetin combination in an ayurvedic dental formulation and the novel method developed in this report is the first of its kind. The developed method is based on the use of very economical solvent, had short chromatographic time and hence can be performed with ease.

\section{CONCLUSION}

The results indicate that selected ayurvedic dental powder contains a number of markers that may be responsible for its therapeutic activity. The developed HPLC method will assist in the standardization of dental powder using biologically active chemical markers. The developed HPLC method for simultaneous determination of ellagic acid and quercetin from ayurvedic dental powder is accurate, precise, reproducible and repeatable. These ayurvedic dental powder also contains a number of other constituents, which are currently the subject of further investigation, apart from those standards studied. With the growing demand for herbal drugs and increased belief in the usage of herbal medicine, the development of a standardization tool will help in maintaining the quality of this important ayurvedic preparation.

\section{ACKNOWLEDGEMENT}

Authors are thankful to Yucca Enterprises, Mumbai Maharashtra for providing gift samples and authors are also thankful to Mumbai University for providing financial support under minor research project scheme.

\section{AUTHORS CONTRIBUTIONS}

All the authors have contributed equally

\section{CONFLICT OF INTERESTS}

Declared none

\section{REFERENCES}

1. Lokhande S, Chougule A, Patil S, Patil V. Need of herbal drug standardization. Int Ayurvedic Med J 2015;3:874-7.
2. Shobhen R, Patel NM, Patel PM. A review on modification of analytical techniques in herbal research. Int J Res Ayurveda Pharm 2011;2:1483-5.

3. Nowak R. Determination of ellagic acid in pseudofruits of some species of roses. Acta Pol Pharm 2006;63:289-92.

4. Tiwari P, Patel RK. Quantification of gallic acid and ellagic acid in arjunarishta by validated HPTLC densitometry. Int J Pharm Sci Res 2012;3:2215-23.

5. Walid E, Hassan M, Mona M. HPLC analysis of quercetin and antimicrobial activity of comparative methanol extracts of shinus molle L. Int J Curr Microbiol Appl Sci 2015;4:550-8.

6. Jain V, Saikh S. Simultaneous RP-HPLC analysis of quercetin and kaempferol in different plant parts of Cissus Quadrangularis. Int J Pharm Pharm Sci 2016;8:138-42.

7. Lee FA, Mun FY, Yvonne T, Peh K, Yusrida D. HPLC method for simultaneous quantitative detection of quercetin and curcuminoids in traditional chinese medicines. J Pharmacopuncture 2014;17:36-49.

8. Thakur AK, Jain V, Hingorani L, Laddha KS. Improved highperformance liquid chromatography-DAD method for the simultaneous analysis of quercetin and kaempferol in the stems of Cissus quadrangularis Linn. Acta Chromatogr 2009;21:95-103.

9. Olena IG. Simultaneous determination of flavonoids and phenolic acids in different parts of prunella vulgaris L. by HPLC-DAD. J Pharmacogn Phytochem 2014;29:1248-54.

10. Vemula VR, Sharma PK. RP-HPLC method development and validation for simultaneous estimation of diclofenac and tolperisone in tablet dosage form. Asian J Pharm Clin Res 2013;6 Suppl 3:186-9.

11. International Conference on Harmonization of Technical Requirements for Registration of Pharmaceuticals for Human use. Validation of Analytical Procedures: Text and Methodology ICH Q2 (R1); 2005.

12. Sarat M, Murali PK, Rambabu C. Development and validation of RPHPLC method for simultaneous estimation of amlodipine besylate and benazepril $\mathrm{Hcl}$ in tablet dosage form. Int J Curr Pharm Res 2012;4:80-4.

13. FDA, Guidance R. Validation of chromatographic methods. center for drug evaluation and research (CDER), Food Drug Administration; 1994. p. 2.

14. FDA, ORA validation and verification guidance for human drug analytical methods. Food and Drug Administration; 2003. p. 1. 